\title{
Genetic variability of the equine casein genes
}

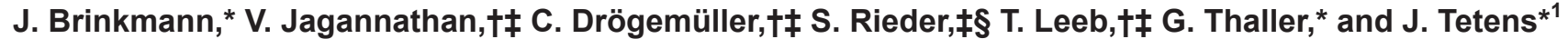 \\ *Institute of Animal Breeding and Husbandry, Christian-Albrechts-University Kiel, D-24098 Kiel, Germany \\ †Institute of Genetics, University of Bern, $\mathrm{CH}-3001$ Bern, Switzerland \\ $\ddagger$ Swiss Competence Center of Animal Breeding and Genetics, University of Bern, Bern University of Applied Sciences HAFL and Agroscope, \\ $\mathrm{CH}-3001$ Bern, Switzerland \\ §Agroscope, Swiss National Stud Farm, CH-1580 Avenches, Switzerland
}

\begin{abstract}
The casein genes are known to be highly variable in typical dairy species, such as cattle and goat, but the knowledge about equine casein genes is limited. Nevertheless, mare milk production and consumption is gaining importance because of its high nutritive value, use in naturopathy, and hypoallergenic properties with respect to cow milk protein allergies. In the current study, the open reading frames of the 4 casein genes CSN1S1 ( $\alpha_{S 1}$-casein), CSN2 ( $\beta$-casein), CSN1S2 $\left(\alpha_{\mathrm{S} 2}\right.$-casein), and CSN3 ( $\kappa$-casein) were resequenced in 253 horses of 14 breeds. The analysis revealed 21 nonsynonymous nucleotide exchanges, as well as 11 synonymous nucleotide exchanges, leading to a total of 31 putative protein isoforms predicted at the DNA level, 26 of which considered novel. Although the majority of the alleles need to be confirmed at the transcript and protein level, a preliminary nomenclature was established for the equine casein alleles.
\end{abstract}

Key words: mare milk, caseins, isoforms, genetic variability

\section{INTRODUCTION}

There is a longstanding tradition of mare milk consumption in countries of the central Asian steppes, such as Mongolia or Kazakhstan (Uniacke-Lowe et al., 2010). In several European countries, mainly Italy, Hungary, the Netherlands, and Germany, consumption of mare milk is gaining more importance and it has been estimated that approximately 1 million kilograms are produced in Europe (Fox and Uniacke, 2010). The exact global production is unknown, but it has been reported that 30 million people worldwide regularly consume horse milk (Martuzzi and Vaccari Simonini, 2010). The increasing interest in mare milk is to a large extent driven by reports on positive health effects. The milk of horses is, for example, tolerated by children

Received November 17, 2015.

Accepted March 9, 2016.

${ }^{1}$ Corresponding author: jtetens@tierzucht.uni-kiel.de suffering from cow milk protein allergies, which affects approximately $2 \%$ of infants nourished with milk replacements based on cow milk (Businco et al., 2000; Curadi et al., 2001).

Despite this importance, knowledge about equine milk proteins and especially their genetic variability is still very limited. The genetic diversity of milk protein genes in typical dairy species, such as cattle (Caroli et al., 2009) and goat (Selvaggi et al., 2014), has been considered in numerous studies and distinct genetic variants have been described at both the protein and the DNA level.

Due to their ability to form micelles, caseins are important for the supply of the neonate with calcium, phosphate, and AA (Lenasi et al., 2003; Uniacke-Lowe et al., 2010). Whereas the casein fraction in bovine milk accounts for about $75 \%$ of the whole milk protein (Martin and Grosclaude, 1993), caseins only make up half of the equine milk protein fraction (Malacarne et al., 2002). The equine casein fraction is divided in $\alpha_{\mathrm{S} 1}-\mathrm{CN}$ (18\%), $\beta-\mathrm{CN}(79 \%), \alpha_{\mathrm{S}^{2}} \mathrm{CN}(1.5 \%)$, and $\kappa-\mathrm{CN}(1.5 \%$; Malacarne et al., 2002; Miranda et al., 2004; Inglingstad et al., 2010). The genes encoding these proteins are located on equine chromosome 3 in a tightly linked $290-\mathrm{kb}$ gene cluster. The order is CSN1S1 (encoding $\left.\alpha_{\mathrm{S1}^{-}} \mathrm{CN}\right)$, CSN2 (encoding $\left.\beta-\mathrm{CN}\right)$, CSN1S2 (encoding $\alpha_{\mathrm{S}_{2}} \mathrm{CN}$ ), and CSN3 (encoding $\mathrm{\kappa}$-CN; Egito et al., 2002; Milenkovic et al., 2002; Lenasi et al., 2003, 2005; Miranda et al., 2004; Girardet et al., 2006; Miclo et al., 2007; Selvaggi et al., 2010). Current knowledge about the individual caseins and their genetic variability is summarized in Table 1. The aim of our study was to provide extended knowledge about the genetic variability of equine casein genes and to identify putative protein variants at the DNA level by analyzing and comparing different horse breeds.

\section{MATERIALS AND METHODS}

\section{Animals and Samples}

Genomic DNA was extracted from hair samples of 198 horses using a modified version of the Miller et al. 
Table 1. Current knowledge about equine casein genes and their genetic variability

\begin{tabular}{|c|c|c|c|c|}
\hline Casein & $\begin{array}{l}\text { Gene } \\
\text { symbol }\end{array}$ & $\begin{array}{l}\text { Length of the } \\
\text { open reading } \\
\text { frame }\end{array}$ & $\begin{array}{l}\text { Location EquCab2.0 } \\
\text { Chrom. } 3 \\
\text { NC_009146.2 }\end{array}$ & Comment \\
\hline$\alpha_{\mathrm{S} 1}$ & $C S N 1 S 1$ & $612 \mathrm{bp}$ & $\begin{array}{l}64,954,285 \ldots \\
64,970,471\end{array}$ & $\begin{array}{l}\text { Full-length cDNA sequence: Lenasi et al. (2003). } \\
\text { Two variants due to exon skipping (Miranda et al., 2004). } \\
\text { Genomic (NC_009146.2) and mRNA (NM_ 001081883.1) } \\
\text { reference sequences differ (c.406C>A). }\end{array}$ \\
\hline$\beta$ & CSN2 & $699 \mathrm{bp}$ & $\begin{array}{l}64,938,110 \ldots \\
64,946,489\end{array}$ & $\begin{array}{l}\text { Full-length cDNA sequence: Lenasi et al. (2003) and Girardet } \\
\text { et al. (2006). } \\
\text { Two smaller variants reported (Miranda et al., 2004). }\end{array}$ \\
\hline$\alpha_{\mathrm{S} 2}$ & CSN1S2 & $642 \mathrm{bp}$ & $\begin{array}{l}64,795,317 \ldots \\
64,811,812\end{array}$ & $\begin{array}{l}\text { First described in } 2000 \text { (Egito et al., 2001; Egito et al., 2002; } \\
\text { Miranda et al., 2004; Ochirkhuyag et al., 2000). } \\
\text { Two major variants }\left(C S N 1 S 2^{*} A, C S N 1 S 2^{*} B\right) \text { due to a } \\
\text { genomic 1.3-kb deletion covering } 2 \text { coding exons (Brinkmann } \\
\text { et al., 2015). }\end{array}$ \\
\hline$\kappa$ & CSN3 & $555 \mathrm{bp}$ & $\begin{array}{l}64,683,856 \ldots \\
64,694,148\end{array}$ & $\begin{array}{l}\text { First described in } 2001 \text { (Iametti et al., 2001; Miranda et al., } \\
\text { 2004). } \\
\text { Full-length cDNA sequence: Lenasi et al. (2003). } \\
\text { Two putative variants described at the DNA level by Hobor et } \\
\text { al. (2006; 2008): Ile383Lys and Thr173Ala. }\end{array}$ \\
\hline
\end{tabular}

(1988) protocol. The horses belonged to 8 breeds that are currently used for mare milk production in Germany. The samples were taken in 2012 on 10 different farms across northern, southern, and eastern Germany. In most cases, actual dairy mares were sampled, but in some instances male relatives of mares that had left the herd or natural service stallions were included in the study. The animals were selected to be as unrelated as possible in a way that only one animal was chosen from groups of relatives such as sisters or dam and offspring. Additionally, individual whole-genome sequence variant calling data of a total 55 horses from 10 different breeds available from other studies were incorporated in the analyses. This was an independent sample and the horses were not related to animals from the ini- tial sample. The animals were sequenced to a mean coverage of $15.8 \times$; bioinformatic details were reported previously (Drögemüller et al., 2014; Frischknecht et al., 2014). In total, 253 horses belonging to 14 different breeds or populations were analyzed (Table 2 ).

\section{DNA Sequencing}

A total of 37 primer pairs (Supplemental Table S1; http://dx.doi.org/10.3168/jds.2015-10652) were designed to amplify all exons contributing to the open reading frames of the genes and adjacent intronic regions. Primer 3 software (Rozen and Skaletsky, 2000) was used based on the genomic reference sequences of the casein genes CSN1S1, CSN2, CSN1S2, and CSN3

Table 2. Animals used in the sequence analysis of the equine casein genes $(\mathrm{n}=253)$

\begin{tabular}{|c|c|c|c|c|}
\hline Breed & Acronym & $\mathrm{SEQ}^{1}$ & WGS $^{2}$ & Total \\
\hline Akhal-Teke & AK & - & 1 & 1 \\
\hline Dairy Crossbreed $^{3}$ & $\mathrm{CB}$ & 21 & - & 21 \\
\hline Argentine Criollo Horse & $\mathrm{CR}$ & 27 & - & 27 \\
\hline Fjord Horse & FJ & 3 & - & 3 \\
\hline Franches-Montagnes & FM & - & 29 & 29 \\
\hline Haflinger & $\mathrm{HF}$ & 39 & 1 & 40 \\
\hline Icelandic Horse & $\mathrm{IC}$ & 25 & 1 & 26 \\
\hline Dutch Warmblood (KWPN) & $\mathrm{WB}_{\mathrm{NL}}$ & - & 1 & 1 \\
\hline Quarter Horse & $\mathrm{QH}$ & 22 & 3 & 25 \\
\hline Russian Heavy Draft & RU & 24 & - & 24 \\
\hline Shetland pony & SP & - & 2 & 2 \\
\hline Swiss Warmblood & $\mathrm{WB}_{\mathrm{CH}}$ & - & 3 & 3 \\
\hline UK Warmblood & $\mathrm{WB}_{\mathrm{UK}}$ & - & 2 & 2 \\
\hline German Warmblood & $\mathrm{WB}_{\mathrm{D}}$ & 37 & 12 & 49 \\
\hline Total & & 198 & 55 & 253 \\
\hline
\end{tabular}

${ }^{1}$ Data from DNA Sanger sequencing.

${ }^{2}$ Data from whole-genome sequencing.

${ }^{3}$ Breeds that are crossed include German Riding Pony, Haflinger Horse, Connemara Pony, New Forest Pony, and further pony breeds to achieve a preferable high milk yield. 
(Acc. No NC_009146.2, EquCab2.0). The genomic reference sequence of CSN1S1 was found to contain a gap spanning a coding exon. A flanking primer pair was designed to close the gap by Sanger sequencing.

The PCR amplification and DNA sequencing were done as described by Gallinat et al. (2013). The sequences obtained were analyzed and compared with the genomic GenBank sequence NC_009146.2 using the software Sequencher 4.9 (Gene Codes Corp., Ann Arbor, MI). To confirm the novelty of the identified variants, a BLAST search (http://blast.ncbi.nlm.nih. gov/Blast.cgi) of the generated sequence data against public databases was conducted. The discrimination of the known CSN1S2 variants A or B was done by fragment length analysis as described by Brinkmann et al. (2015). For the breeds in our study, allele frequencies for all observed variants of CSN1S1, CSN2, CSN1S2, and $C S N 3$ were calculated by counting.

\section{RESULTS}

The complete open reading frames of the 4 casein genes were successfully sequenced for a minimum of 197 (CSN1S1) and a maximum of 244 (CSN3) horses belonging to 14 breeds. The numbers significantly differ between breeds, because only animals with complete sequence data were counted here and animals with failed exons in Sanger sequencing or insufficient coverage in whole-genome sequencing were excluded (details are given in Table 3). No systematic failure of particular animals or PCR assays indicating the possible presence of structural variation were observed. Six, 4, 8, and 13 variants were identified in CSN1S1, CSN2, CSN1S2, and $C S N 3$, respectively. This makes a total of 31 casein variants identified at the DNA level, 2 of which do represent signal peptide variants and 26 of which can be regarded as novel. Moreover, 11 synonymous nucleotide exchanges were identified. None of the variants denoted as novel in the current study were found in public databases by BLAST, confirming their novelty. Interestingly, one polymorphism in CSN1S2 (c.386G >A/p. Arg129Gln) was not found in the CSN1S2 sequences of Equus caballus, but was identified in the predicted mRNA sequence of CSN1S2 in Equus przewalskii (Acc. No. XM_008510698.1). The counted allele frequencies of all variants are summarized in Table 3, allele frequencies were only determined in breeds with at least 10 samples available.

Provisional names were assigned to putative isoforms as identified from the haplotypes found in the sample $\left(C S N 1 S 1^{*} A\right.$ to $C S N 1 S 1^{*} D ; C S N 2{ }^{*} A$ to $C S N 2{ }^{*} C$; CSN1S2*A to $C S N 1 S 2^{*} F ; C S N{ }^{*} A$ to $C S N 3{ }^{*} M$ ). The numbering of positions within the gene refers to the coding sequence for the full-length proteins, including the signal peptide. For $\alpha_{\mathrm{S}^{-}} \mathrm{CN}$, this results in a 220-AA protein, resulting from the mRNA sequence NM_001081883.1 plus exon 7 (24 bp), which is missing in this sequence. The full-length protein of $\beta-\mathrm{CN}$ is $241 \mathrm{AA}$, resulting from the coding sequence NM_001081852.1 plus exon 5 (24 bp), which is missing in this sequence. Resulting from the reference sequence KP658381.1, the full-length $\alpha_{\mathrm{S}^{-}} \mathrm{CN}$ is $231 \mathrm{AA}$. The reference sequence NM_001081884.1 codes for $\kappa$-CN, which is 185 AA.

\section{CSN1S1}

The genomic reference sequence NC_009146.2 (EquCab2.0) was found to contain a gap with an estimated size of 674 bp spanning exon 16, which is present in the mRNA reference sequence NM_001081883.1. The gap was closed by Sanger sequencing of a PCR product revealing an exact gap size of $731 \mathrm{bp}$ (see Supplemental Figure S1; http://dx.doi.org/10.3168/jds.2015-10652; the sequence was deposited in GenBank under Acc. No. KU145145).

Subsequently, sequence data of 197 animals were compared to find putative variants. As compared with the genomic reference sequence (Acc. No. NC_009146.2), 5 previously unknown nonsynonymous nucleotide exchanges were identified within the open reading frame of CSN1S1 defining 5 putative protein isoforms (Table 4 ). One of the variants is predicted to affect the signal peptide sequence; the corresponding allele with the signal peptide variant was termed $C S N 1 S 1^{*} A *$. No allele matching the mRNA reference sequence NM_001081883.1 was found in the analyzed samples.

The allele $C S N 1 S 1^{*} A$ corresponding to the genomic reference sequence was the most common one among the examined animals and was found in all breeds (Table 3, Figure 1). A signal peptide variant (c.25C $>$ A/Leu9Ile) defines the allele $C S N 1 S 1^{*} A *$, which was common in all breeds except Akhal-Teke, Dutch Warmblood, and Shetland pony. A nucleotide exchange c.88G $>$ A (Glu30Lys) characterizes allele $C S N 1 S 1^{*} B$, which was identified in Criollo Horses, Fjord Horses, and Shetland ponies. Allele $C S N 1 S 1^{*} C$ is defined by an additional transition (c.470T $>\mathrm{C} / \mathrm{p}$.Val157Ala). This haplotype was exclusively found in Icelandic Horses. Allele $C S N 1 S 1^{*} D$ differs from allele $\mathrm{A}$ by a $\mathrm{T}>\mathrm{G}$ transversion in position 428 of the ORF (c.428T $>$ G/p.Leu143Arg) and was detected in Haflinger and Icelandic Horses. Allele $C S N 1 S 1^{*} E$ is caused by a single nucleotide exchange from $\mathrm{C}$ to $\mathrm{A}$ in position 329 (c.329C $>\mathrm{A}$; pPro110Ala) and was found in German Warmblood Horses as well as in Franches-Montagnes. Additionally, a synonymous 
EQUINE CASEIN GENES

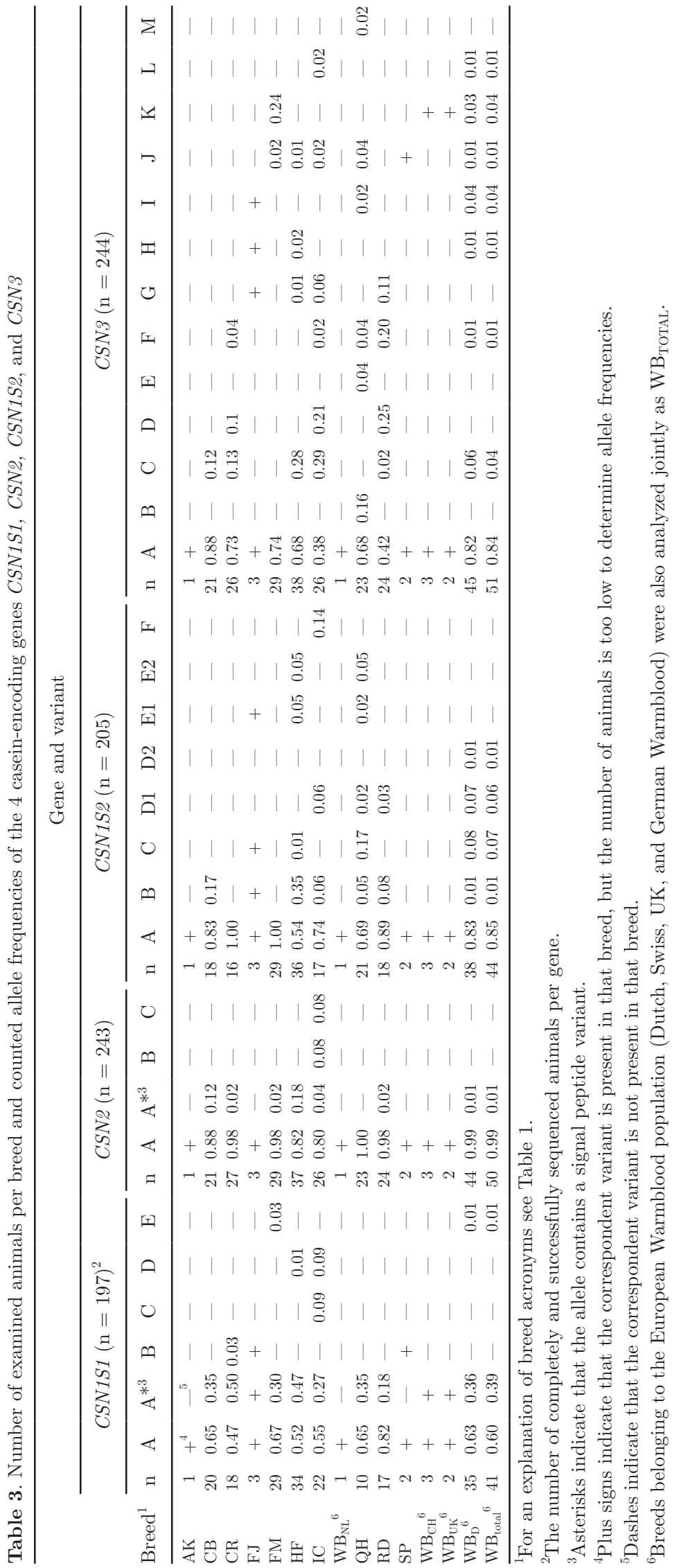


Table 4. Sequence variants and putative protein alleles of the equine CSN1S1 gene

\begin{tabular}{|c|c|c|c|c|c|c|}
\hline \multirow{2}{*}{$\begin{array}{l}\text { Position in open } \\
\text { reading frame } \\
\text { and protein }\end{array}$} & \multicolumn{6}{|c|}{$\alpha_{\mathrm{S} 1}-\mathrm{CN}$ protein alleles } \\
\hline & $\begin{array}{c}\text { Ref. } \\
\text { Seq. }{ }^{1} \mathrm{~A}\end{array}$ & $\mathrm{~A}^{*}$ & B & C & D & $\mathrm{E}$ \\
\hline$\overline{c .25^{2}}$ & $\mathrm{CTT}$ & ATT & & & & \\
\hline p.9 & Leu & Ile & & & & \\
\hline c. 88 & GAA & & AAA & AAA & & \\
\hline p.30 & Glu & & Lys & Lys & & \\
\hline c. 329 & $\mathrm{CCA}$ & & & & & $\mathrm{CAA}$ \\
\hline p.110 & Pro & & & & & Gln \\
\hline c. 428 & CTT & & & & CGT & \\
\hline p.143 & Leu & & & & Arg & \\
\hline c. 470 & GTA & & & GCA & & \\
\hline p. 157 & Val & & & Ala & & \\
\hline
\end{tabular}

nucleotide exchange was found (c.633G $>$ A), which was in perfect linkage disequilibrium to the sequence polymorphism defining allele $C S N 1 S 1^{*} D$.

\section{CSN2}

The open reading frame of the CSN2 gene was successfully examined in 243 horses and 4 previously unknown nonsynonymous nucleotide exchanges, each defining a putative protein isoform, were detected (Table 5). Also for this gene, one of the variants affects the signal peptide. The genomic reference sequence (NC_009146.2) was designated as $C S N 2{ }^{*} A$ and represented the most common allele at this locus (Table 3 , Figure 1). The allele with the signal peptide variant $C S{ }^{2}{ }^{*} A$ is characterized by a single nucleotide exchange c.16C $>\mathrm{T}$ leading to a predicted AA exchange from leucine to phenylalanine (p.Leu6Phe) in the signal peptide; this variant was detected with allele frequencies up to 0.2 in the crossbred horses for dairy production, Criollo Horses, Franches-Montagnes, Haflinger Horses, Icelandic Horses, Russian Heavy Draft, and German Warmblood. A single transition (c.277G $>$ A/p.Val93Ile) defines allele $C S N 2^{*} B$, which was found to be rare and was only detected in Icelandic Horses. A haplotype of 2 nucleotide exchanges in positions 91 and 479 of the open reading frame gives rise to allele $\mathrm{CSN} 2{ }^{*} \mathrm{C}$ (Table 5). Furthermore, 6 synonymous nucleotide exchanges were found in the equine CSN2 gene (c.36C > T; c.102C > T; c. $123 \mathrm{G}>\mathrm{A} ;$ c. $162 \mathrm{G}>\mathrm{A} ;$ c. $417 \mathrm{C}>\mathrm{T} ;$ c. $465 \mathrm{C}>\mathrm{T})$.

\section{CSN1S2}

Sequencing of the CSN1S2 gene was successfully completed in 205 animals. A total of 6 nonsynonymous single nucleotide variants and one large deletion leading to 8 distinct putative protein isoforms were identified, 6 of which were considered novel (Table 6).

Allele CSN1S2*A (Acc. No. KT368778) corresponding to the genomic reference sequence (NC_009146.2) was found to be most frequent across all analyzed breeds. Allele $C S N 1 S 2^{*} B$ (Acc. No. KT368779), which has already been described by Brinkmann et al. (2015), differs from allele $A$ by the presence of a 1,339 -bp deletion spanning 2 coding exons. It was found in Crossbred Horses, Fjord Horses, Icelandic Horses, Quarter Horses, Russian Heavy Draft Horses, and German Warmbloods, with allele frequencies ranging from 0.01 in Warmblood Horses to 0.35 in Haflinger Horses. The putative allele $C S N 1 S 2{ }^{*} C$, on the other hand, defined by a single nucleotide exchange c.398C $>\mathrm{T}$ leading to a predicted AA exchange from threonine to isoleucine in position 133 of the protein (Table 6), was found to be rare; it only occurred at low frequencies in Fjord, Haflinger, and Quarter Horses, as well as German Warmbloods. A nonsynonymous transition in position 218 of the ORF (c.218C $>$ T/p.Thr73Ile) defines allele $D$. This exchange was found to occur on the long allele $C S N 1 S 2^{*} A$ as well as on the short allele $B$ and the resulting alleles were thus designated $C S N 1 S 2{ }^{*} D 1$ and $C S N 1 S 2{ }^{*} D 2$, respectively. Allele $D 1$ was detected at low frequencies in Icelandic and Quarter Horses as well as Russian Heavy Drafts and German Warmbloods, whereas CSN1S2*D2 was found in German Warmblood Horses only (Table 3 ). Equivalently, allele $E$, which is defined by $2 \mathrm{nu}-$ cleotide exchanges in codons 129 and 217 (see Table 6 for details) was found in conjunction with the long as well as the short variant and the respective alleles arising from those haplotypes were termed $C S N 1 S 2^{*} E 1$ and $C S N 1 S 2{ }^{*} E 2$. The former was detected in Fjord, Haflinger, and Quarter Horses, whereas the latter was only found in Haflinger and Quarter Horses. Finally, 2 

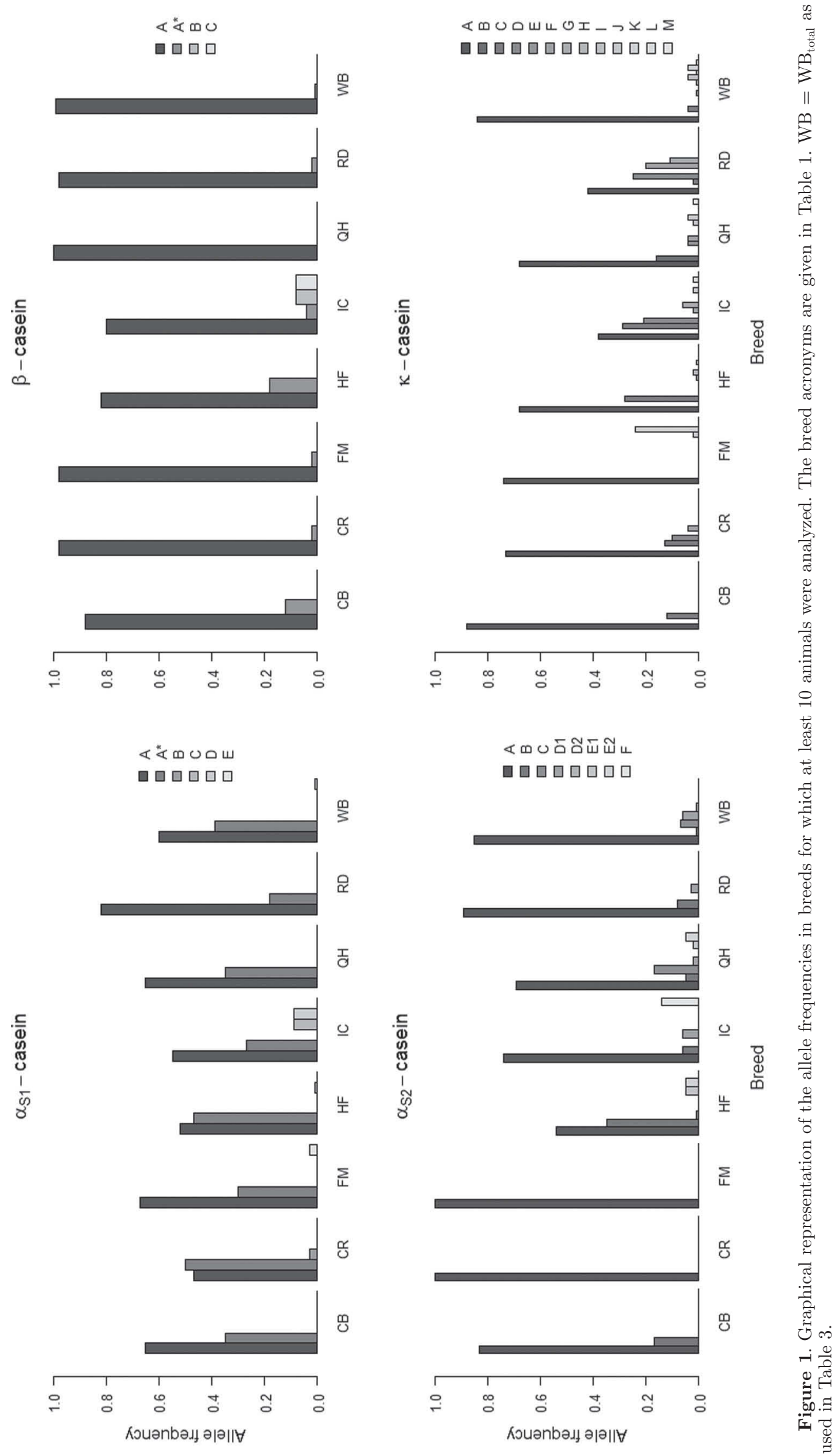
Table 5. Sequence variants and putative protein alleles of the equine CSN2 gene

\begin{tabular}{|c|c|c|c|c|}
\hline \multirow{2}{*}{$\begin{array}{l}\text { Position in open } \\
\text { reading frame } \\
\text { and protein }\end{array}$} & \multicolumn{4}{|c|}{$\beta-\mathrm{CN}$ protein alleles } \\
\hline & $\begin{array}{l}\text { Ref. } \\
\text { Seq. }{ }^{1} \mathrm{~A}\end{array}$ & $A^{*}$ & B & $\mathrm{C}$ \\
\hline$\overline{c .16^{2}}$ & CTT & TTT & & \\
\hline p. 6 & Leu & Phe & & \\
\hline c. 91 & CTT & & & TTT \\
\hline p.31 & Leu & & & Phe \\
\hline c. 277 & GTT & & ATT & \\
\hline p.93 & Val & & Ile & \\
\hline c. 479 & CTG & & & $\mathrm{CCG}$ \\
\hline p. 160 & Leu & & & Pro \\
\hline
\end{tabular}

${ }^{1}$ Variant $C S N 2 * A$ is corresponding to the genomic reference NC_009146.2.

${ }^{2}$ c.16 is located in the sequence coding for the signal peptide and leads to the signal peptide variant $C S N 2^{*} A *$.

transitions in positions 182 and 640 of the ORF (Table 6) characterize the rare allele $C S N 1 S 2^{*} F$, which was exclusively detected in Icelandic Horses. Additionally, 4 synonymous nucleotide exchanges were detected in equine CSN1S2 (c.21C>T; c. $24 \mathrm{C}>\mathrm{T} ; \quad$ c. $225 \mathrm{~A}>\mathrm{G}$; c.402A $>\mathrm{G}$ ). The synonymous nucleotide exchange c. $225 \mathrm{~A}>\mathrm{G}$ was always observed in combination with allele $C S N 1 S 2^{*} F$ in Icelandic horses.

\section{CSN3}

The ORF of the CSN3 gene was successfully resequenced in 244 animals revealing 6 nonsynonymous nucleotide exchanges, 4 of which had not been described before. A total of 13 putative protein isoforms were predicted from these nucleotide exchanges (Table 7 ).
The allele represented by the genomic reference sequence (Acc. No. NC_009146.2) was denoted $C S N 3^{*} A$. It was found to be the most common one in all examined breeds with frequencies of up to 0.88 . Four alleles, namely $C S N 3^{*} B, C S N 3^{*} F, C S N 3^{*} H$, and $C S N 3^{*} J$, were found to differ from the genomic reference by only one nucleotide exchange each (Table 7 ). Allele $B$, which is characterized by an AA exchange from threonine to alanine in codon 29, occurred at a rather high frequency of 0.16 (Table 3) in Quarter Horses, whereas allele $F$, defined by an asparagine to lysine exchange in codon 24, was seen at a frequency of 0.2 in Russian Heavy Drafts. Allele $H$, which is also defined by a threonine to alanine exchange, but at codon 173 , has previously been described in several Slovenian horse breeds as well as Haflinger Horses (Hobor et al., 2006, 2008) and in the current study was found to occur in Haflinger Horses and German Warmbloods. The putative protein isoform $C S N 3^{*} J$ is characterized by the occurrence of a premature stop codon leading to a truncated proteinlacking AA positions 183 to 185; the allele was found in several breeds at low frequencies. The variants defining alleles $B$ and $J$ were also identified in conjunction with the variant characterizing the putative allele $\operatorname{CSN}^{*}{ }^{*} C$ (Table 7), which was found in high frequencies of up to almost 0.3 in Haflinger and Icelandic Horses (Table 3, Figure 1). Likewise, the nucleotide exchanges defining alleles $H$ and $J$ were found together in a haplotype giving rise to the rare allele $C S N 3^{*} L$. The variations causing alleles $F$ and $H$, respectively, were found to jointly define $C S N 3^{*} G$, which was only found in Haflinger and German Warmblood. A further nonsynonymous nucleotide exchange was identified in codon 22 (Table 7). This variant did not occur independently, but was only seen

Table 6. Sequence variants and putative protein alleles of the equine CSN1S2 gene

\begin{tabular}{|c|c|c|c|c|c|c|c|c|}
\hline \multirow{2}{*}{$\begin{array}{l}\text { Position in open } \\
\text { reading frame } \\
\text { and protein }\end{array}$} & \multicolumn{8}{|c|}{$\alpha_{\mathrm{S} 2}$ CN protein alleles } \\
\hline & $\begin{array}{c}\text { Ref. } \\
\text { Seq. }{ }^{\circ} \mathrm{A}\end{array}$ & B & $\mathrm{C}$ & D1 & D2 & E1 & E2 & $\mathrm{F}$ \\
\hline c. 182 & AGG & & & & & & & AAG \\
\hline p.61 & Arg & & & & & & & Arg \\
\hline c. 218 & $\mathrm{ACA}$ & & & ATA & ATA & & & \\
\hline p.73 & Thr & & & Ile & Ile & & & \\
\hline c. $199-249^{2}$ & ins. & del. & & & del. & & del. & \\
\hline p. $67-83$ & & & & & & & & \\
\hline c. 386 & CGG & & & & & CAG & CAG & \\
\hline p.129 & Arg & & & & & Gln & Gln & \\
\hline c.398 & $\mathrm{ACC}$ & & ATC & & & & & \\
\hline p.133 & Thr & & Ile & & & & & \\
\hline c. 640 & CGG & & & & & & & TGG \\
\hline p.214 & Arg & & & & & & & Tyr \\
\hline c. 65 & AGA & & & & & AGT & AGT & \\
\hline p. 217 & Arg & & & & & Ser & Ser & \\
\hline
\end{tabular}

${ }^{1}$ Variant $C S N 1 S 2^{*} A$ corresponds to the genomic reference NC_009146.2.

${ }^{2}$ This variant represents a large deletion, which has been described by Brinkmann et al. (2015). 
along with the exchange in codon 24, together defining the haplotype of the rare allele $C S N 3^{*} I$ (Tables 3 and 7). Finally, a previously described (Hobor et al., 2006, 2008) nonsynonymous nucleotide exchange was found in codon 128 (c.282T $>\mathrm{A})$, which was also not detected independently. Against the background of allele L, for example, it defines $C S N 3^{*} K$, which was the second most frequent variant in Franches-Montagnes (Tables 3 and 7, Figure 1). Furthermore, the nucleotide exchanges were found to exist in additional combinations, namely defining alleles $C S N 3^{*} D, C S N 3^{*} E$, and $C S N 3^{*} M$ (Table 7 ). Allele $D$ was found to exhibit a high frequency in Icelandic Horses, whereas variants $M$ and $E$ were only found in Quarter Horses, with the latter differing from the reference sequence in 5 positions.

\section{DISCUSSION}

\section{Methodology}

Within the current study, DNA sequencing of the open reading frames was used to identify putative protein variants of the equine caseins. Thereby, 26 new casein variants, including 2 signal peptide variants, were detected. As discussed by Gallinat et al. (2013), the main advantages of this methodology are the practicability and the better availability of DNA samples as compared with protein samples, especially when breeds from different countries are considered. The main disadvantage, however, is that neither the actual expression of variants nor posttranslational modifications can be evaluated; furthermore, variations due to differential alternative splicing cannot readily be detected. For $\alpha_{\mathrm{S1}}$ and $\beta$-CN, for example, shorter variants have been identified (Lenasi et al., 2003; Miranda et al., 2004; Girardet et al., 2006; Table 1), which can only be characterized at the transcript or protein level.

Allele frequencies within breeds were determined by counting. These frequencies have to be taken with care, because the number of animals per breed was rather small. Some breeds were even represented by 3 or less individuals (Table 3), and in these cases no allele frequencies were determined. Furthermore, relationships between animals might distort allele frequencies; although the animals were unrelated according to the pedigree information available from the owners, we cannot completely exclude cases of unknown relationships. Nevertheless, the figures give an overview of the breed distribution for the identified variants. The provisional nomenclature for the alleles established here will be subject to confirmation at the protein level. Furthermore, in some instances 2 or more variants were only found heterozygously within one gene, hampering the unequivocal definition of haplotypes. This was the case for $C S{ }^{3}{ }^{*} I$. Due to the large number of identified variants it was, however, necessary to establish a nomenclature to simplify referencing and discussion.

The selection of animals for the study was initially limited to breeds that are actually used for mare milk production in Germany. The Haflinger Horse is an especially favored and well-established breed for dairy production in Germany and other countries. Especially in southern Germany, however, many Haflingers are also specifically bred for sports and pleasure purposes. Consequently, market prices for the male offspring of dairy mares are low. Some farmers prefer breeds that are rare in Germany, such as the Criollo or the Russian Heavy Draft, to achieve higher prices for the male offspring. Thus, a comparatively wide spectrum of breeds has been covered within the current study.

Table 7. Sequence variants and putative protein alleles of the equine CSN3 gene

\begin{tabular}{|c|c|c|c|c|c|c|c|c|c|c|c|c|c|}
\hline \multirow{2}{*}{$\begin{array}{l}\text { Position in open } \\
\text { reading frame } \\
\text { and protein }\end{array}$} & \multicolumn{13}{|c|}{$\kappa-\mathrm{CN}$ protein alleles } \\
\hline & $\begin{array}{c}\text { Ref. } \\
\text { Seq. }{ }^{1} \mathrm{~A}\end{array}$ & $\mathrm{~B}$ & $\mathrm{C}$ & $\mathrm{D}$ & $\mathrm{E}$ & $\mathrm{F}$ & G & $\mathrm{H}$ & I & $\mathrm{J}$ & K & $\mathrm{L}$ & $\mathrm{M}$ \\
\hline p. 22 & Val & & & & Ala & & & & Ala & & & & \\
\hline c. 72 & $\mathrm{AAC}$ & & & $\mathrm{AAG}$ & $\mathrm{AAG}$ & $\mathrm{AAG}$ & $\mathrm{AAG}$ & & AAG & & & & \\
\hline p.24 & Asn & & & Lys & Lys & Lys & Lys & & Lys & & & & \\
\hline c. $383^{2}$ & ATA & & & & AAA & & & & & & AAA & & \\
\hline p.128 & Ile & & & & Lys & & & & & & Lys & & \\
\hline c. $517^{2}$ & $\mathrm{ACC}$ & & & GCC & GCC & & GCC & GCC & & & GCC & GCC & GCC \\
\hline p.173 & Thr & & & Ala & Ala & & Ala & ala & & & Ala & Ala & Ala \\
\hline c. 547 & CAA & & TAA & TAA & TAA & & & & & TAA & TAA & TAA & \\
\hline p.183 & Gln & & Stop & Stop & Stop & & & & & Stop & Stop & Stop & \\
\hline
\end{tabular}

${ }^{1}$ Variant $C S N 1 S 2{ }^{*} A$ is corresponding to the genomic reference NC_009146.2.

${ }^{2}$ Hobor et al., 2006, 2008. 
Notably, one of the sampled populations represents a crossbreed including German Riding Pony, Haflinger Horse, Connemara Pony, and New Forest Pony, as well as further pony breeds. This breed has especially been produced for dairy farming and selected for milkability and milk yield. It remains unclear, however, how phenotypes have been recorded and selection has been conducted in this crossbreed.

\section{Breed-Specific Variation Patterns}

The degree of variability observed within this study differs between breeds. Generally, this has to be interpreted very carefully, because the breeds are not equally represented. Some breeds are actually only represented by 3 or less individuals. Nevertheless, some basic figures can be drawn from the observations.

The Icelandic Horse exhibited the highest degree of variability within this study. A total of 19 different casein gene alleles were found in this breed, 4 of which $\left(C S N 1 S 1{ }^{*} C, C S N 2{ }^{*} B, C S N 2{ }^{*} C, C S N 1 S 2^{*} F\right)$ were found exclusively within this breed. This seems unexpected in the first instance, because the breed originates from a small founder population. These animals were brought to Iceland approximately 1,100 yr ago and the population has been closed since then (Adalsteinsson, 1981). However, the samples were not taken on Iceland and Hreidarsdóttir et al. (2014) reported a higher diversity in terms of effective founders for abroad as compared with the Icelandic population.

With 18 different alleles, the second most isoforms were identified in German Warmblood Horses, followed by Quarter Horses with 16 alleles, 3 of which were exclusively found in this breed $\left(C S N 3^{*} B, C S N 3^{*} E\right.$, $\left.C S N 3^{*} M\right)$. Whereas alleles $E$ and $M$ were found to be rare, $C S N 3^{*} B$ had an allele frequency of 0.15 and might thus be designated as a characteristic allele in Quarter Horses. A comparatively low degree of variation was found in the crossbreed for dairy production, with only 8 casein gene variants. This is noteworthy as several different breeds have been crossed here. It might, however, be possible that selection for milk yield that is performed on this particular farm has reduced the casein variability, because some variants have a strong effect on the target trait.

\section{Evolution of the Casein Variants}

Based on the current data, it is in many instances difficult to draw conclusions about the exact evolution of the putative casein alleles. In most cases, however, a putative ancestral allele and possible routes of variant evolution could be inferred. Although these conclu- sions do hold within the current data set, additional results from more ancestral breeds, for example from the central Asian steppes, might be needed to better understand variant evolution.

In the case of $C S N 1 S 1$, allele $A$ seems to represent the ancestral haplotype because of the high allele frequencies distributed over all examined breeds (Table 3, Figure 1). The alleles $C S N 1 S 1^{*} A *, C S N 1 S 1^{*} B$, $C S N 1 S 1^{*} D$, and $C S N 1 S 1^{*} E$ differ from $C S N 1 S 1^{*} A$ by only one nucleotide exchange each and might have directly evolved from the ancestral allele. Allele $C S N 1 S 1^{*} C$ can be derived from allele $B$ by one additional nonsynonymous nucleotide exchange in position 470 of the open reading frame.

Likewise, allele $C S N^{2}{ }^{*} A$ was found in all breeds at high frequencies, which might indicate an ancestral status of this allele. The other alleles were found to be rare (Table 3 ) and differ from allele $A$ by $1(C S N 2 * A *$, $\left.C S N 2{ }^{*} B\right)$ or $2\left(C S N 2^{*} C\right)$ nucleotide exchanges (Table $5)$.

The situation for CSN1S2 seems to be more complicated. In a previous study, we identified 2 major alleles $(C S N 1 S 2 * A$ and $C S N 1 S 2 * B)$ differing in length by 17 AA due to a large genomic deletion spanning 2 coding exons and determined that the deletion has probably occurred before the ancestor of present day asses and zebras diverged from the horse lineage (Brinkmann et al., 2015). Alleles $C S N 1 S 2^{*} C$ and $C S N 1 S 2^{*} F$ differ from the long reference allele $A$ by 1 and 2 mutations, respectively, and might have evolved from this allele (Table 6). Two other alleles, $C S N 1 S 2^{*} D$ and $C S N 1 S 2^{*} E$, however, do occur in conjunction with both the long and the short allele; the resulting alleles were termed $D 1 / D 2$ and E1/E2, respectively (Table 6). Overall, these are rare, but allele $D 1$ does occur more frequently than $D^{2}$ (Table 3). Thus, it is possible, that CSN1S2*D1 might have evolved from the long allele $C S N 1 S 2^{*} A$ and that $C S N 1 S 2{ }^{*} D 2$ represents a recombinant haplotype. The alleles E1 and E2 are comparably rare and it is possible that the underlying polymorphisms have been segregating together for a long period. Notably, one of the polymorphisms defining these alleles (c.386 A>G) was found also in the CSN1S2 sequences of Equus przewalskii (Acc. No. XM_008510698.1) by BLAST analysis, which supports this hypothesis.

Several alleles of $C S N 3$ were detected in the current study. It is likely that either $C S N 3^{*} A$ or $C S N 3^{*} F$ might be an ancestral allele in the current data set. From $C S N 3^{*} A$ allele $C S N 3^{*} B$ could have evolved by one sequence variant (c.85A $>\mathrm{G})$ and a further mutation (c.547 C>T) might have led to $\operatorname{CSN} 3{ }^{*} C$. Allele $C S N 3^{*} F$ seems to be the basis for the development of the alleles $\operatorname{CSN}^{*} G$ and $C S N 3^{*} I$, each caused by an 
additional exchange (Table 7). From $C S N 3^{*} G$, allele $C S N 3^{*} D$ might have evolved, which subsequently could have led to the development of $C S N 3^{*} E$. However, due to the large number of alleles arising from the various possible haplotypes, the evolution of $C S N 3$ cannot be further elucidated based on the current data.

\section{Consequences for Production and Human Consumption}

In the dairy sector, mare milk is a high-priced niche product, which is marketed under several health claims. The main reason for this is due to the fact production is costly, as mares can only be milked with a foal at foot. Thus, selection for milk yield or contents has not taken place so far. Attempts to select for these traits are furthermore hampered by a lack of routine milk recording schemes, which would be difficult to implement, because the foal's milk consumption cannot readily be determined (Doreau and Martuzzi, 2006). A main criterion in the selection of dairy mares would, however, be ease of milking (Doreau and Boulot, 1989; Doreau and Martuzzi, 2006), but with the exception of the aforementioned crossbreed for dairy production, no selection takes place and the potential is still unexploited.

For other dairy species, the effects of casein isoforms on performance traits are known (Martin et al., 2002; Boettcher et al., 2004; Heck et al., 2009), but for the above reasons this cannot be analyzed in dairy mares. However, several of the health benefits empirically ascribed to horse milk might be attributable to the protein fraction and thus depend on the pattern of protein variants. These benefits include putative positive effects on gastrointestinal ulcers, digestive and cardiovascular diseases, diarrhea, and gastritis. Other diseases, such as tuberculosis, anemia, chronic hepatitis, and nephritis, have traditionally been treated with horse milk or kumis, an alcoholic fermented mare milk drink, especially in Russian sanatoria (Park et al., 2008). Several reasons for the effectiveness were suggested, such as the fatty acid pattern or the high content of lysozyme and lactoferrin. Also peptides arising from the hydrolysis of $\beta$-CN may be responsible for health effects. Mare milk and kumis contain peptides with hypotensive activity, but specific research on bioactive peptides from mare milk is scarce (Doreau and Martin-Rosset, 2002). Some current studies provide the first scientific evidence of the health benefits of mare milk, with studies about beneficial effects on atopic dermatitis (Foekel et al., 2009), chronic inflammatory bowel diseases (Schubert et al., 2009), and cardiovascular diseases (Chen et al., 2010). Knowledge about the equine milk protein genes might provide a basis for further studies about the ef- fect of mare milk on human health, especially related to the release of bioactive peptides.

Mare milk is also considered a hypoallergenic foodstuff. It has been shown, in vitro and in vivo, that this milk is tolerated by $96 \%$ of children affected by cow milk allergy (Businco et al., 2000; Curadi et al., 2001). Cow milk allergy is an IgE-mediated allergic reaction causing a broad range of symptoms, such as atopic dermatitis, constipation, and infantile colic. This condition affects approximately $2 \%$ of infants when nourished with milk replacements on a cow milk basis (Heine et al., 2002). Among the caseins, $\alpha_{\mathrm{S} 1-} \mathrm{CN}$ has been identified as the protein with the highest allergenic potential, and many individuals affected by CMA show a high titer of IgE specific for this protein (Shek et al., 2005; Ruiter et al., 2006; Gaudin et al., 2008; Schulmeister et al., 2009; Lisson, 2014). Several reasons for the low allergenicity of mare milk are discussed; for example, the absence of the epitopes relevant for the IgE binding. In the current study, a signal peptide variant leading to the allele $\operatorname{CSN} 1 S 1^{*} A$ * was detected, which might principally cause a reduced content or absence of $\alpha_{S 1}$ CN . This variant was found to be very common, with allele frequencies of up to 0.5. We were, however, not able to assess whether the altered signal peptide affects protein expression; this should be subject to further studies.

\section{CONCLUSIONS}

Within the current study, the genetic diversity of equine casein genes was assessed at the DNA level in 253 horses belonging to 14 different breeds or populations. Thereby, 32 different putative casein isoforms were identified, 26 of which can be considered novel. This study gives, for the first time, a comprehensive overview of genetic variability at the casein loci in horses, including noteworthy findings such as the high degree of variability in the Icelandic horse breed, which was overrepresented in the current study. The results provide a foundation for further research into the properties of the equine milk protein fraction.

\section{ACKNOWLEDGMENTS}

This project was founded by the German Federal Ministry of Education and Research (Bonn, Germany) within the competence network "Food Chain Plus" (FoCus, grant no. 0315539A). The authors thank all the mare milk producers for providing samples, Julia Tetens (Christian-Albrechts-University Kiel, Germany) for her help with sample collection, and Gabriele Ottzen-Schirakow (Christian-Albrechts-University) for expert technical assistance. 


\section{REFERENCES}

Adalsteinsson, S. 1981. Origin and conservation of farm animal populations in Iceland. Z. Tierz. Züchtungsbiol. 98:258-264.

Boettcher, P. J., A. Caroli, A. Stella, S. Chessa, E. Budelli, F. Canavesi, S. Ghiroldi, and G. Pagnacco. 2004. Effects of casein haplotypes on milk production traits in Italian Holstein and Brown Swiss cattle. J. Dairy Sci. 87:4311-4317.

Brinkmann, J., T. Koudelka, J. K. Keppler, A. Tholey, K. Schwarz, G. Thaller, and J. Tetens. 2015. A novel variant of equine $\alpha$-S2-casein due to a $1.3 \mathrm{~kb}$ deletion spanning two coding exons. PLoS ONE 10:e0139700

Businco, L., P. G. Giampietro, P. Lucenti, F. Lucaroni, C. Pini, G. Di Felice, P. Iacovacci, C. Curadi, and M. Orlandi. 2000. Allergenicity of mare's milk in children with cow's milk allergy. J. Allergy Clin. Immunol. 105:1031-1034.

Caroli, A. M., S. Chessa, and G. J. Erhardt. 2009. Invited review: Milk protein polymorphisms in cattle: effect on animal breeding and human nutrition. J. Dairy Sci. 92:5335-5352.

Chen, Y., Z. Wang, X. Chen, Y. Liu, H. Zhang, and T. Sun. 2010 Identification of angiotensin I-converting enzyme inhibitory peptides from koumiss, a traditional fermented mare's milk. J. Dairy Sci. 93:884-892.

Curadi, M. C., P. G. Giampietro, P. Lucenti, and M. Orlandi. 2001. Use of mare milk in pediatric allergology. Pages 647-649 in Proc. ASPA Congr. Rec. Prog. Anim. Prod. Sci. Associazione Scientifica di Produzione Animale, Italy.

Doreau, M., and S. Boulot. 1989. Recent knowledge on mare milk production: A review. Livest. Prod. Sci. 22:213-235.

Doreau, M., and W. Martin-Rosset. 2002. Dairy animals: horse. Pages 630-637 in Encyclopedia of Dairy Sciences. H. Roginski, J. A. Fuquay, and P. F. Fox, ed. Academic Press, London, UK.

Doreau, M., and F. Martuzzi. 2006. Milk yield of nursing and dairy mares. Pages 77-87 in Nutrition and Feeding of the Broodmare. N. Miraglia, and W. Martin-Rosset, ed. Academic Publishers, Wageningen, the Netherlands..

Drögemüller, M., V. Jagannathan, M. M. Welle, C. Graubner, R. Straub, V. Gerber, D. Burger, H. Signer-Hasler, P. A. Poncet, S. Klopfenstein, R. von Niederhausen, J. Tetens, G. Thaller, S. Rieder, C. Drogmuller, and T. Leeb. 2014. Congenital hepatic fibrosis in the Franches-Montagnes horse is associated with the polycystic kidney and hepatic disease 1 (PKHD1) gene. PLoS ONE 9:e110125

Egito, A. S., J.-M. Girardet, L. Miclo, D. Mollé, G. Humbert, and J.-L. Galliard. 2001. Susceptibility of equine $\kappa$ - and $\beta$-caseins to hydrolysis by chymosin. Int. Dairy J. 11:885-893.

Egito, A. S., L. Miclo, C. López, A. Adam, J. M. Girardet, and J L. Gaillard. 2002. Separation and characterization of mares' milk alpha(s1)-, beta-, kappa-caseins, gamma-casein-like, and proteose peptone component 5-like peptides. J. Dairy Sci. 85:697-706.

Foekel, C., R. Schubert, M. Kaatz, I. Schmidt, A. Bauer, U. C. Hipler, H. Vogelsang, K. Rabe, and G. Jahreis. 2009. Dietetic effects of oral intervention with mare's milk on the Severity Scoring of Atopic Dermatitis, on faecal microbiota and on immunological parameters in patients with atopic dermatitis. Int. J. Food Sci. Nutr. 60(Suppl 7):41-52.

Fox, P. F., and T. Uniacke. 2010. Chemical and physico-chemical properties of equid milk. Page 39 in Book of Abstracts of the 61st Annual Meeting of the European Association for Animal Production. Heraklion, Crete Island, Greece. Wageningen Academic Publishers, Wageningen, the Netherlands.

Frischknecht, M., M. Neuditschko, V. Jagannathan, C. Drögemüller, J. Tetens, G. Thaller, T. Leeb, and S. Rieder. 2014. Imputation of sequence level genotypes in the Franches-Montagnes horse breed. Genet. Sel. Evol. 46:63.

Gallinat, J. L., S. Qanbari, C. Drögemüller, E. C. G. Pimentel, G. Thaller, and J. Tetens. 2013. DNA-based identification of novel bovine casein gene variants. J. Dairy Sci. 96:699-709.

Gaudin, J.-C., H. Rabesona, Y. Choiset, G. Yeretssian, J. M. Chobert, B. Sakanyan, M. Drouet, and T. Haertle. 2008. Assessment of the immunoglobulin E-mediated immune response to milk-specific proteins in allergic patients using microarrays. Clin. Exp. Allergy 38:686-693.

Girardet, J.-M., L. Miclo, S. Florent, D. Mollé, and J.-L. Gaillard. 2006. Determination of the phosphorylation level and deamidation susceptibility of equine beta-casein. Proteomics 6:3707-3717.

Heck, J. M. L., A. Schennink, H. J. F. van Valenberg, H. Bovenhuis, M. H. Visker, J. A. van Arendonk, and A. C. van Hooijdonk. 2009. Effects of milk protein variants on the protein composition of bovine milk. J. Dairy Sci. 92:1192-1202.

Heine, R. G., S. Elsayed, C. S. Hosking, and D. J. Hill. 2002. Cow's milk allergy in infancy. Curr. Opin. Allergy Clin. Immunol. 2:217225.

Hobor, S., T. Kunej, and P. Dovč. 2008. Polymorphisms in the kappa casein (CSN3) gene in horse and comparative analysis of its promoter and coding region. Anim. Genet. 39:520-530.

Hobor, S., T. Kunej, T. Lenasi, and P. Dovč. 2006. Kappa casein gen (CSN3) in horse: Kapa kazeinski gen (CSN3) pri konju genetic variability in exon 1 and 4 genetska variabilnost v eksonu 1 in 4 . Acta Agric. Slov. 88:83-89.

Hreidarsdóttir, G., T. Árnason, V. Svansson, and J. Hallson. 2014 Analysis of the history and population structure of the Icelandic horse using pedigree data and DNA analyses. Icel. Agric. Sci. 27:63-79.

Iametti, B. S., G. Tedeschi, E. Oungre, and F. Bonomi. 2001. Primary structure of kappa-casein isolated from mares' milk. J. Dairy Res. 68:53-61.

Inglingstad, R. A., T. G. Devold, E. K. Eriksen, H. Holm, M. Jacobsen, K. H. Liland, E. O. Rukke, and G. E. Vegaurd. 2010. Comparison of the digestion of caseins and whey proteins in equine, bovine, caprine and human milks by human gastrointestinal enzymes. Dairy Sci. Technol. 90:549-563.

Lenasi, T., N. Kokalj-Vokac, M. Narat, A. Baldi, and P. Dovč. 2005 Functional study of the equine beta-casein and kappa-casein gene promoters. J. Dairy Res. 72:34-43.

Lenasi, T., I. Rogelj, and P. Dovč. 2003. Characterization of equine cDNA sequences for $\alpha \mathrm{S} 1-, \beta$ - and $\kappa$-casein. J. Dairy Res. 70:29-36.

Lisson, M. 2014. Appearance of epitopes in bovine milk protein variants, their allergenicity and potential use in human nutrition. Zugl.: Gießen, Univ., Diss., 2014. 1. Aufl. Édition scientifique. VVB Laufersweiler, Gießen, Germany.

Malacarne, M., F. Martuzzi, A. Summer, and P. Mariani. 2002. Protein and fat composition of mare's milk: Some nutritional remarks with reference to human and cow's milk. Int. Dairy J. 12:869-877.

Martin, P., and F. Grosclaude. 1993. Improvement of milk protein quality by gene technology. Livest. Prod. Sci. 35:95-115.

Martin, P., M. Szymanowska, L. Zwierzchowski, and C. Leroux. 2002. The impact of genetic polymorphisms on the protein composition of ruminant milks. Reprod. Nutr. Dev. 42:433-459.

Martuzzi, F., and F. Vaccari Simonini. 2010. Advances on equine milk and derivatives for human consumption. Page 40 in Book of Abstracts of the 61st Annual Meeting of the European Association for Animal Production. Heraklion, Crete Island, Greece. Wageningen Academic Publishers, Wageningen, the Netherlands.

Miclo, L., J.-M. Girardet, A. S. Egito, and D. Mollé., P, and J. L 2007. The primary structure of a low-Mr multiphosphorylated variant of beta-casein in equine milk. Proteomics 7:1327-1335.

Milenkovic, D., P. Martin, G. Guérin, and C. Leroux. 2002. A specific pattern of splicing for the horse $\alpha$ S1-Casein mRNA and partial genomic characterization of the relevant locus. Genet. Sel. Evol. 34:509

Miller, S. A., D. D. Dykes, and H. F. Polesky. 1988. A simple salting out procedure for extracting DNA from human nucleated cells. Nucleic Acids Res. 16:1215.

Miranda, G., M.-F. Mahé, C. Leroux, and P. Martin. 2004. Proteomic tools to characterize the protein fraction of Equidae milk. Proteomics 4:2496-2509.

Ochirkhuyag, B., J.-M. Chobert, M. Dalgalarrondo, and T. Haertlé 2000. Characterization of mare caseins. Identification of alpha-S1and alpha-S2-caseins. Lait 80:223-235. 
Park, Y. W., H. Zhang, B. Zhang, and L. Zhan. 2008. Mare milk. Page 294 in Handbook of Milk of Non-Bovine Mammals. Y. W. Park, and G. F. W. Haenlein, ed. Wiley, Ames, IA.

Rozen, S., and H. Skaletsky. 2000. Primer3 on the WWW for general users and for biologist programmers. Methods Mol. Biol. 132:365386.

Ruiter, B., V. Trégoat, L. M'rabet, J. Garssen, C. A. BruijnzeelKoomen, E. F. Knol, and E. Hoffen. 2006. Characterization of T cell epitopes in alphas1-casein in cow's milk allergic, atopic and non-atopic children. Clin. Exp. Allergy 36:303-310.

Schubert, R., C. Kahle, E. Kauf, J. Hofmann, I. Hubert, B. Gruhn, R. Hafer, H. Vogelsang, and G. Jahreis. 2009. Dietetic efficacy of mare's milk for patients with chronic inflammatory bowel diseases - Clinical study. Ernährung 33:314-321.

Schulmeister, U., H. Hochwallner, I. Swoboda, M. Focke-Tejkl, B. Gellar, M. Nystrand, A. Harlin, J. Thalhammer, S. Scheibhofer, W. Keller, B. Niggeman, S. Quirce, A. Mari, G. Pauli, U. Herz, R.
Valenta, and S. Spitzauer. 2009. Cloning, expression, and mapping of allergenic determinants of alphaS1-casein, a major cow's milk allergen. J. Immunol. 182:7019-7029.

Selvaggi, M., V. Laudadio, C. Dario, and V. Tufarelli. 2014. Major proteins in goat milk: An updated overview on genetic variability. Mol. Biol. Rep. 41:1035-1048.

Selvaggi, M., A. R. Pesce Delfino, and C. Dario. 2010. Exon 1 polymorphisms in the equine CSN3 gene: SNPs distribution analysis in Murgese horse breed. Anim. Biotechnol. 21:252-256.

Shek, L. P. C., L. Bardina, R. Castro, H. A. Sampson, and K. Beyer. 2005. Humoral and cellular responses to cow milk proteins in patients with milk-induced IgE-mediated and non-IgE-mediated disorders. Allergy 60:912-919.

Uniacke-Lowe, T., T. Huppertz, and P. F. Fox. 2010. Equine milk proteins: Chemistry, structure and nutritional significance. Int. Dairy J. 20:609-629. 